\title{
A Study to Assess the Correlation between Academic Test Anxiety and Self-Esteem among Undergraduate Students
}

\author{
Timi Thomas ${ }^{1}$ Gincy Joseph ${ }^{2}$ Shynee Paul ${ }^{3}$ \\ ${ }^{1}$ Department of Obstetrics and Gynaecological Nursing, Nitte Usha \\ Institute of Nursing Sciences, Nitte (Deemed to be University), \\ Mangalore, Karnataka, India \\ 2 NUINS Cum ENLS state co-ordinator, JeevaRaksha, Bangalore, \\ Karnataka, India \\ 3 Department of Obstetrics and Gynaecological Nursing, PVS College \\ of Nursing, Calicut, Kerala, India \\ J Health Allied Sci ${ }^{\mathrm{NU}} 2022 ; 12: 417-422$.
}

Abstract

Keywords
- correlation
- academic test anxiety
- self-esteem
- self-confidence
- undergraduates

Address for correspondence Timi Thomas, Assistant Professor, Department of Obstetrics and Gynaecological Nursing, Nitte Usha Institute of Nursing Sciences, Nitte (Deemed to be University), Mangalore 575018, Karnataka, India (e-mail: timi@nitte.edu.in).

Introduction The time of examination and evaluation is a stressful period where stress is on its highest levels. To some extent, low level of stress can help in motivating the students; however, on the contrary more stress can be discouraging. It will make students exhausted, overwhelmed, and confused. So, the present study focuses on assessing the academic test anxiety and self-esteem among undergraduates. The objectives of the study were: determining the academic test anxiety and self-esteem among students and find out the correlation and association between academic test anxiety and self-esteem.

Materials and Methods A quantitative research approach had been adopted and descriptive correlational survey design was used to identify the academic test anxiety and self-esteem among first year students from selected constituent colleges of NITTE (Deemed to be University) at Paneer campus. The sample consisted of 300 first year undergraduate students. The participants were selected using convenient sampling technique. The data were collected using the sociodemographic pro forma, standardized Westside Test Anxiety Scale and State Self-Esteem Scale. The data were computed using descriptive statistics and inferential statistics like Karl Pearson's correlation coefficient test, Fisher's exact value, and chi-square value.

Result Majority of (79.9\%) of the participants were in the age group of 18 to 19 years. The mean age of the participants was $18.56 \pm 0.928$ with minimum age 17 and maximum age of 21 . Regarding entry level percentage of marks (Pre-University Course/ +2 ), $34.7 \%$ of participants secured with more than $80 \%$ of marks in their entry level examination followed by $38.2 \%$ of the participants scoring between 70 and $79 \%$ and only $16(5.6 \%)$ participants counted between 45 and 59\%. Majority (76\%) of the participants were females. The study reveals that $32.3 \%$ of the participants experienced moderate level of test anxiety and $17 \%$ of the participants experienced severe level of

published online

February 9, 2022
DOI https://doi.org/ $10.1055 / \mathrm{s}-0042-1742464$. ISSN 2582-4287.
(C) 2022. Nitte (Deemed to be University). All rights reserved.

This is an open access article published by Thieme under the terms of the Creative Commons Attribution-NonDerivative-NonCommercial-License, permitting copying and reproduction so long as the original work is given appropriate credit. Contents may not be used for commercial purposes, or adapted, remixed, transformed or built upon. (https://creativecommons.org/ licenses/by-nc-nd/4.0/)

Thieme Medical and Scientific Publishers Pvt. Ltd., A-12, 2nd Floor, Sector 2, Noida-201301 UP, India 
test anxiety followed by $34.7 \%$ participants experiencing mild levels of test anxiety. The mean test anxiety score was $2.97 \pm 0.55$ which indicates that average participants were showing moderate level of test anxiety. There is a significant medium positive correlation between academic test anxiety and self-esteem ( $r$ value $=0.497$ and $p \leq$ $0.001)$. As the $p$-value was more than $0.05(p=0.09, p=0.86)$, there is no significant association found between previous academic performance with level of academic test anxiety or self-esteem.

Conclusion The study concludes that, students' self-esteem can be enhanced and test anxiety can be reduced by creating an enabling environment for mentoring where they can practice assertiveness skills which will in turn boost their confidence to perform all academic tasks successfully.

\section{Introduction}

Test anxiety is a common global issue, and every year it affects the academic performance of millions of students worldwide. ${ }^{1}$ Previous research studies report that the prevalence rate among students toward test anxiety is 10 to $30 \%$. In Iran, a prevalence rate of $17.2 \%$ has been reported for test anxiety. ${ }^{2}$ In the process of development, children and adolescents experience a broad spectrum of anxieties, which are sometimes so dangerous that it can create problems in their academic performance and daily life. ${ }^{3}$ In the typical academic environment, entrance examinations and formative and summative examinations represent a potent stressor that can impact a student's performance in school and university. On the other hand, academic self-confidence and self-esteem plays a significant role in students' learning. Students with higher level of academic confidence and self-esteem tend to visualize their success, think soundly, and commit themselves to the challenges at hand and they are proved to be high achievers. ${ }^{4}$ Conversely, students with low self-confidence and self-esteem are more likely to focus on how things might dwell in their personal deficiencies. In essence, these individuals tend to focus on the problems of the circumstance rather than the possibilities of success. ${ }^{5}$ The 2019 Annual Report of the Centre for Collegiate Mental Health reported that anxiety continues to be the most common problem, diagnosed among students who seek services at university counseling centers. ${ }^{6}$ So, the present study focuses on determining the academic test anxiety and self-esteem among undergraduate students.

\section{Methods}

\section{Study Design and Participants}

A quantitative research approach was adopted in the study. A descriptive correlational survey design was used to identify the academic test anxiety and self-esteem among first year students from selected constituent colleges of NITTE (Deemed to be University) at Paneer campus. The sample size was calculated using the formula of mean difference and standard deviation (SD), with $\alpha=$ level of significance (5\%), $P=$ anticipated prevalence (25\%), $\mathrm{d}=$ relative precision (5\%), and the estimated sample size was 300 undergraduate students. The participants were selected using convenient sampling technique. Inclusion criteria for study participants were: (1) students those who have test anxiety, (2) willing to participate, and (3) those that are mentally and physically fit at the time of the study. The data was collected from January 21, 2021 to January 28, 2021.

\section{Data Collection Instruments}

The data were collected using the sociodemographic pro forma, standardized Westside Test Anxiety Scale and State Self-Esteem Scale. Demographic pro forma of the student consists of age in years, gender, religion, entry level percentage of marks (Pre-University Course $[\mathrm{PUC}] /+2$ ), type of family, number of siblings, father's and mother's education, and father's and mother's occupation. The academic test anxiety scale is a standardized tool, and it is a 5-point scale consisting of 10 statements and rating is done in sequence from always true (5), usually true (4), sometimes true (3), seldom true (2), and never true (1). The academic test anxiety tool is categorized as follows: 1.0 to 2.4 (Normal), 2.5 to 2.9 (Mild), 3.0 to 3.4 (Moderate), 3.5 to 3.9 (Severe), and 4.0 to 5.0 (Extremely high anxiety). Similarly, the State SelfEsteem Scale is also a standardized tool, and it consists of 20 -item scale that measures a participant's self-esteem at a given point in time. The 20 items are subdivided into 3 components of self-esteem: (1) performance self-esteem, social self-esteem, and appearance self-esteem. All items are answered using a 5 -point scale $(1=$ not at all, $2=$ a little bit, $3=$ somewhat, $4=$ very much, $5=$ extremely). Items 2,4 , $5,7,8,10,13,15,16,17,18,19$, and 20 are reverse-scored. The reliability of the Westside Test Anxiety Scale and State Self-Esteem Scale was done, and the internal consistency was measured with Cronbach's alpha using SPSS statistics 23 version and it was found to be 0.953 and 0.79 , respectively. Pretesting of the tool was done to identify problems with the data collection instruments and to find possible solutions. Pretesting was performed on November 15, 2020 to identify the inadequacies of the data collection instruments and to make due modifications as required. The investigator conducted the pilot study after obtaining permission from the Principal, Nitte Usha Institute of Nursing Sciences (NUINS), from January 18, 2021 to January 19, 2021 with 10 nursing 
students. The pilot study helped the investigator to identify the inadequacies of the plan and made the due modifications as required. The investigator introduced herself and explained the purpose of the study and consent was obtained from the undergraduate students prior to the administration of data collection instruments.

\section{Data Collection Procedure}

Before the data collection, an informed consent and participant information sheet was administered to the participants to assure confidentiality of data among the participants. Informed consent, participant information sheet, and the data collection instruments were administered together in the Google form. Permission for carrying out the main study was obtained from the concerned authorities of constituent colleges like: NUINS, Nitte Gulabi Shetty Memorial Institute of Pharmaceutical Sciences (NGSMIPS), and Nitte University Centre for Science Education and Research (NUCSER). The investigator conducted the main study from January 21, 2021 to January 28, 2021. The data analysis was done using SPSS 20.

\section{Result}

\section{Baseline Information}

The majority (230; 79.9\%) of the participants were in the age group of 18 to 19 years. The mean age of the participants was $18.56 \pm 0.928$ with minimum age 17 and maximum age of 21 . Regarding entry level percentage of marks (PUC/ +2 ), $34.7 \%$ participants secured with more than $80 \%$ of marks in their entry level examination followed by $38.2 \%$ of the participants scoring between 70 and 79\%. Only 16 (5.6\%) participants counted between 45 and $59 \%$ and majority (76\%) of the participants were females. With regards to type of family, $64.2 \%$ of participants were from nuclear family and more than half of the participants had one sibling. With reference to parents' education, $<10 \%$ of the participants' parents had only Masters education. The common occupation (50\%) of the participants' parents was farming and $59 \%$ of the participants' mothers were housewife (-Tables 1 and $\mathbf{2}$ ).

The classification of the academic test anxiety score and level of self-esteem were analyzed by using descriptive statistics such as frequency, percentage mean, and SD.

The notable fact from the above table is that, $32.3 \%$ of the participants experienced moderate level of test anxiety and $17 \%$ of the participants experienced severe level of test anxiety followed by $34.7 \%$ participants experiencing mild levels of test anxiety.

In self-esteem scale, the subcomponent on performance self-esteem items the participants were with mean \pm SD of $23.38 \pm 4.04$ and the minimum and maximum score was 9 and 35, respectively. The study participants scored a mean of 24 ( \pm SD 4.04) with minimum 11 and maximum 35 scores. The table also shows that, in the subcomponent on appearance self-esteem items the participants were with mean \pm SD of $20.03 \pm 3.1$ with minimum 10 and maximum 28 scores. The total self-esteem score among the study participants were with mean \pm SD of $67.41 \pm 8.55$ and minimum and maximum scores were 32 and 92, respectively (-Table $\mathbf{3}$ ).
Table 1 Frequency $(f)$ and percentage (\%) distribution of demographic variables of participants

\begin{tabular}{|c|c|c|}
\hline Demographic characteristics $(n=300)$ & $f$ & $\%$ \\
\hline \multicolumn{3}{|l|}{ Age in years } \\
\hline$<18$ & 26 & 8.7 \\
\hline $18-19$ & 236 & 78.7 \\
\hline $20-21$ & 38 & 12.6 \\
\hline \multicolumn{3}{|l|}{ Gender } \\
\hline Male & 75 & 25.0 \\
\hline Female & 225 & 75.0 \\
\hline \multicolumn{3}{|l|}{ Religion } \\
\hline Hindu & 84 & 28 \\
\hline Christian & 135 & 45 \\
\hline Muslim & 43 & 14.3 \\
\hline Any other & 38 & 12.7 \\
\hline \multicolumn{3}{|l|}{ Entry level percentage of marks (PUC/+2) } \\
\hline $45-59 \%$ & 16 & 5.3 \\
\hline $60-69 \%$ & 62 & 20.8 \\
\hline $70-79 \%$ & 116 & 38.6 \\
\hline$>80 \%$ and above & 106 & 35.3 \\
\hline \multicolumn{3}{|l|}{ Type of family } \\
\hline Nuclear family & 185 & 61.6 \\
\hline Joint family & 102 & 34 \\
\hline Extended family & 13 & 4.4 \\
\hline \multicolumn{3}{|l|}{ Number of siblings } \\
\hline Nil & 39 & 13 \\
\hline One & 147 & 49 \\
\hline Two & 85 & 28.4 \\
\hline$<$ Two & 29 & 9.6 \\
\hline \multicolumn{3}{|l|}{ Father's education } \\
\hline SSLC & 42 & 14 \\
\hline PUC & 78 & 26 \\
\hline Diploma & 62 & 20.6 \\
\hline Graduate & 90 & 30 \\
\hline Master's & 28 & 9.3 \\
\hline \multicolumn{3}{|l|}{ Mother's education } \\
\hline SSLC & 35 & 11.6 \\
\hline PUC & 76 & 25.3 \\
\hline Diploma & 73 & 24.3 \\
\hline Graduate & 101 & 33.6 \\
\hline Master's & 15 & 5 \\
\hline \multicolumn{3}{|l|}{ Father's occupation } \\
\hline Professional & 42 & 14 \\
\hline Semiprofessional & 96 & 32 \\
\hline Clerical/Shop owner/Farmer & 123 & 41 \\
\hline Skilled worker & 39 & 13 \\
\hline
\end{tabular}


Table 1 (Continued)

\begin{tabular}{|l|l|l|}
\hline Demographic characteristics $(\boldsymbol{n}=\mathbf{3 0 0})$ & $f$ & $\%$ \\
\hline Mother's occupation & & \\
\hline Professional & 53 & 17.6 \\
\hline Semiprofessional & 65 & 21.6 \\
\hline Clerical/Shop owner/HW & 182 & 60.6 \\
\hline
\end{tabular}

Abbreviations: HW, housewife; PUC, Pre-University Course; SSLC, Secondary School Leaving Certificate.

Table 2 Distribution of academic test anxiety score and level of self-esteem among undergraduate students

\begin{tabular}{|c|c|c|c|c|}
\hline $\begin{array}{l}\text { Academic test anxiety } \\
\text { score }(n=300)\end{array}$ & \multicolumn{2}{|l|}{$f$} & \multicolumn{2}{|l|}{$\%$} \\
\hline Normal (1-2.4) & \multicolumn{2}{|l|}{42} & \multicolumn{2}{|l|}{14} \\
\hline Mild (2.5-2.9) & \multicolumn{2}{|l|}{112} & \multicolumn{2}{|l|}{37.3} \\
\hline Moderate (3-3.4) & \multicolumn{2}{|l|}{97} & \multicolumn{2}{|l|}{32.3} \\
\hline Severe $(3.5-3.9)$ & \multicolumn{2}{|l|}{40} & \multicolumn{2}{|l|}{13.8} \\
\hline Extremely high anxiety (4-5) & \multicolumn{2}{|l|}{09} & \multicolumn{2}{|l|}{3} \\
\hline \multicolumn{5}{|c|}{ Components of self-esteem $(n=300)$} \\
\hline Subcomponent & Mean & SD & Min & Max \\
\hline Performance self-esteem & 23.38 & 4.04 & 9 & 35 \\
\hline Social self-esteem & 24 & 4.04 & 11 & 35 \\
\hline Appearance self esteem & 20.03 & 3.1 & 10 & 28 \\
\hline Total self-esteem core & 67.41 & 8.55 & 32 & 92 \\
\hline
\end{tabular}

Abbreviation: SD, standard deviation.

Table 3 Correlation between academic test anxiety and selfesteem among undergraduate students

\begin{tabular}{|l|l|l|l|l|}
\hline Variables & Mean & SD & $r$ value & $t$ value \\
\hline $\begin{array}{l}\text { Academic } \\
\text { test anxiety }\end{array}$ & 2.97 & 0.55 & 0.497 & $\begin{array}{l}0.000 \\
(<0.001)\end{array}$ \\
\cline { 1 - 3 } Self-esteem & 67.41 & 8.55 & & \\
\hline
\end{tabular}

Abbreviation: SD, standard deviation.

The normality of the data was computed using onesample Kolmogorov- Smirnov test and the $p$-values were found $>0.05$, hence to analyze the correlation between academic test anxiety and self-esteem the researcher decided to use Karl Pearson's correlation coefficient test.
- Table 4 indicates that there is a significant medium positive correlation between academic test anxiety and selfesteem ( $r$ value $=0.497$ and $p \leq 0.001)$. Hence, the research hypothesis $\mathrm{H} 1$ is accepted at $5 \%$ level of significance ( - Table 5).

\section{Discussion}

University and college students live in a social context that expects efficiency, productivity, competitiveness, and individual accomplishments and that measures and provides grades/ awards for their achievements. ${ }^{7}$ Since stress and anxiety can negatively affect the graduate's quality of life in terms of physical and mental health, the investigators were determined to assess the academic test anxiety and self-esteem level among undergraduate students. The present study is strongly supported by a study conducted by Al Khatib on exam anxiety among nursing students at Al-Ahliyya Amman University ${ }^{8}$ in Jordan in the year 2019. The demographic details of the study show that the majority (64\%) of the study participants was between the age group of 18 and 21 years and 59\% of the participants are females. Another study conducted by Vaz et $\mathrm{al}^{9}$ reveals that the majority (90.3\%) of the participants were females and the mean age of the group was 20 . The present study was supported by another study conducted by Gouda et $\mathrm{al}^{10}$, which shows that the mean age of the participant in the study was $20.18 \pm 1.6$ and majority of them are females.

The study reveals that $32.3 \%$ of the participants experienced moderate level of test anxiety and $17 \%$ of the participants experienced severe level of test anxiety followed by $34.7 \%$ participants experiencing mild levels of test anxiety. The mean test anxiety score was $2.97 \pm 0.55$ which indicates that average participants were showing moderate level of test anxiety. Mary et $\mathrm{al}^{11}$ found that $77.2 \%$ of the students experienced a mild level and $19.6 \%$ experienced a moderate level of anxiety. A study conducted by Tsegay et $\mathrm{al}^{12}$ on prevalence and determinants of test anxiety among medical students in Addis Ababa, Ethiopia, revealed that $41 \%$ of students experienced moderate levels of anxiety. Putwain ${ }^{13}$ reported that $54 \%$ of U.K. university students reached the subthreshold for test anxiety. Another study conducted among pharmacy students reveals that $30 \%$ had mild anxiety, $56 \%$ had moderate anxiety, and $14 \%$ had a high degree of test anxiety. The present study findings are inconsistent with the study conducted by Dodson ${ }^{14}$ among nursing students to

Table 4 Association between levels of test anxiety with academic grade received in the previous entry level examination

\begin{tabular}{|c|c|c|c|c|c|c|c|}
\hline \multirow{2}{*}{$\begin{array}{l}\text { Entry level percentage } \\
\text { of marks }(\mathrm{PUC} /+2)\end{array}$} & \multicolumn{5}{|c|}{ Level of test anxiety } & \multirow[t]{2}{*}{ Fisher's exact value } & \multirow[t]{2}{*}{$p$-Value } \\
\hline & Normal & Mild & Moderate & Severe & Extremely severe & & \\
\hline $45-59 \%$ & 4 & 4 & 6 & 1 & 1 & \multirow[t]{4}{*}{18.87} & \multirow[t]{4}{*}{0.09} \\
\hline $60-69 \%$ & 6 & 26 & 23 & 5 & 2 & & \\
\hline $70-79 \%$ & 1 & 5 & 10 & 24 & 40 & & \\
\hline$>80 \%$ and above & 15 & 31 & 26 & 24 & 4 & & \\
\hline
\end{tabular}

Abbreviation: PUC, Pre-University Course.

Note: As the $p$-value was more than $0.05(p=0.09)$ there is no significant association found between previous academic performance with level of academic test anxiety. Hence, the null hypothesis is accepted at 0.05 level of significance ( $\mathbf{- T a b l e ~ 5 ) . ~}$ 
Table 5 Association between levels of self-esteem with academic grade received in the previous entry level examination

\begin{tabular}{|l|l|l|l|l|}
\hline \multirow{2}{*}{$\begin{array}{l}\text { Entry level percentage } \\
\text { of marks (PUC/+2) }\end{array}$} & Level of self-esteem & \multirow{2}{*}{ Chi-square value } & \multirow{2}{*}{$p$-Value } \\
\cline { 2 - 3 } & High level of self-esteem & Low level of self-esteem & \multirow{2}{*}{0.78} & \\
\hline $45-59 \%$ & 10 & 6 & \\
\hline $60-69 \%$ & 62 & 27 & \\
\hline $70-79 \%$ & 110 & 51 & \\
\hline$>80 \%$ and above & 100 & 48 & \\
\hline
\end{tabular}

Abbreviation: PUC, Pre-University Course.

Note: As the $p$-value was more than $0.05(p=0.86)$ there is no significant association found between previous academic performance with level of self-esteem. Hence, the null hypothesis is accepted at 0.05 level of significance.

explore the relationship between test anxiety level and academic achievement. The study findings reported that students with low test anxiety were only $3.8 \%$ and severe test anxiety $33.1 \%$. Moderate test anxiety was observed among $63.1 \%$ of students. The study findings are consistent with the findings of the study conducted by Al Khatib, ${ }^{8}$ which shows that $54 \%$ of the study participants had medium (76-104) levels of exam anxiety.

The study reveals that there is a significant medium positive correlation between academic test anxiety and self-esteem ( $r$ value $=0.497$ and $p \leq 0.001$ ). Hence, the research hypothesis $\mathrm{H} 1$ is accepted at $5 \%$ level of significance. The relation between self-esteem and anxiety has only rarely been studied (Mustafa et $\mathrm{al}^{15}$ ). Self-esteem might serve as a protective factor, as a moderator, mediator, or simply a result of emotional well-being or difficulties. Overall, the available research suggests that high self-esteem may have positive consequences for the well-being and success of the individual and that low self-esteem may be a risk factor for negative outcomes. Another study conducted by Shahidi ${ }^{16}$ on the effectiveness of mindfulness-based stress reduction (MBSR) on emotion regulation and test anxiety in female high school students shows that the MBSR program has had continuous significant effects on test anxiety $(F=70.74$, $p=0.000)$. It has also had significant effects on emotion regulation $(F=70.74, p=0.000)$. However, on the self-blame subscale $(F=2.335, p=0.126)$ the MBSR program was not significant. $^{16}$

The study findings reveals that as the $p$-value was more than $0.05(p=0.09, p=0.86)$ there is no significant association found between previous academic performance with level of academic test anxiety or self-esteem. Hence, the null hypothesis is accepted at 0.05 level of significance. No comparative studies were found.

\section{Conclusion}

The examination anxiety level might interfere with everyday functioning like studies, daily activities, and social life among students. Anxiety is a major predictor of academic performance and various studies have demonstrated that it has a detrimental effect. Students with higher level of anxiety will achieve a lower academic performance and greater anxiety is associated with poorer academic achievement. To some extent, low level of stress can help in motivating the students; however, on the contrary more stress can be discouraging. Exam anxiety will make students exhausted, overwhelmed, and confused. Students who reported high levels of stress during examinations were less satisfied with their life factors that contribute to poor self-esteem as well self-confidence. To improve emotion regulation and thus test anxiety and self-confidence the practice of mindfulness meditation have its positive effects on developing a conscious and nonjudgmental attitude, which can in turn improve one's self-control, self-regulation, and self-monitoring on their behaviors and guide them toward recovery. Hence, educational institutions should offer stress interventions/psychological interventions or mind-body therapies such as MBSR, meditation, or yoga therapy in school to improve student's quality of life and ensure their physical and psychological health at the pivotal age of adolescence.

\section{Ethical Considerations}

The present study fits into the principles defined in the Declaration of Helsinki (World Medical Association, 2013). The study was reviewed and approved by the Institutional Ethics Committee of the Nitte Usha Institute of Nursing Sciences, NITTE (Deemed to be University) and the Reference number was: NUINS/CON/NU/IEC/2020-21/995.

\section{Authors' Contributions}

T.T., G.J., and S.P. conceptualized the study, contributed to protocol development, data collection, and final writing of the report. G.J. performed the data analysis and final editing of the report. The pilot study and the main study were supervised, and the final draft of the article was finalized for publication.

Funding

The study was funded by NU research grant. The University research Grant No was NUSR218-177.

\section{Conflict of Interest}

The authors have extensively contributed to the research study, from the origin of the study to data collection and writing the report. Thus, there is no conflict of interest. 
422 Correlation between Academic Test Anxiety and Self-Esteem among Students Thomas et al.

\section{Acknowledgments}

The authors thank the NITTE (Deemed to be University) for granting the amount to undertake the study and all study participants for making this project possible.

\section{References}

1 Hill KT, Miller LM. Auditory attentional control and selection during cocktail party listening. Cereb Cortex 2010;20(03): 583-590

2 Alsina-Jurnet I, Carvallo-Beciu C, Gutiérez-Maldonado J. Validity of virtual reality as a method of exposure in the treatment of test anxiety. Behav Res Methods 2007;39(04):844-851

3 Abolghasemi A, Mehrabizadeh-Honarmand M, Najarian B, Shokrkon $\mathrm{H}$. The effectiveness of therapeutic methodology of stress inoculation training and systematic desensitization in test anxiety students. J Psychol 2004;8(29):3-21

4 Cheraghian B, Fereidooni Moghadam M, Baraz-Pardjani SH, Bavarsad N. Test anxiety and its relationship with academic performance among nursing students. J Knowl Health 2008;3(3-4):25-29

5 Hong E, Karstensson L. Antecedents of state test anxiety. J Contemp Education Psychol 2002;27(02):348-367

6 Mazzone L, Ducci F, Scoto MC, Passaniti E, D'Arrigo VG, Vitiello B. The role of anxiety symptoms in school performance in a community sample of children and adolescents. BMC Public Health 2007;7:347

7 Spielberger CD, Vagg PR. Test Anxiety: A Transactional Process Model. USA: Taylor and Francis; 1995
8 Al Khatib H. Exam anxiety among nursing students at Al-Ahliyya Amman University and its relationship with some variables. Int J Appl Psychol 2019;9(04):110-116

9 Vaz CJ, Pothiyil TD, George LS, Alex S, Pothiyil DI, Kamath A. Factors influencing examination anxiety among undergraduate nursing students: an exploratory factor analysis. J Clin Diagn Res 2018;12(07):16-18

10 Gouda S, Luong MT, Schmidt S, Bauer J. Students and teachers benefit from mindfulness-based stress reduction in a schoolembedded pilot study. Front Psychol 2016;7:590

11 Mary RA, Marslin G, Franklin G, Sheeba CJ. Test anxiety levels of board exam going students in Tamil Nadu, India. BioMed Res Int 2014;2014:578323

12 Tsegay L, Shumet S, Damene W, Gebreegziabhier G, Ayano G. Prevalence and determinants of test anxiety among medical students in Addis Ababa, Ethiopia. BMC Med Educ 2019;19(01): 423

13 Putwain DW. Test anxiety in UK schoolchildren: prevalence and demographic patterns. Br J Educ Psychol 2007;77(Pt 3):579-593

14 Dodson J. The Effects of Mindfulness on Test Anxiety in Nursing Students. Diss. Kansas City: University of Missouri-Kansas City; 2021

15 Mustafa S, Melonashi E, Shkembi F, Besimi K, Fanaj N. Anxiety and self-esteem among university students: comparison between Albania and Kosovo. Procedia Soc Behav Sci 2015;205:189-194

16 Shahidi S, Akbari H, Zargar F. Effectiveness of mindfulness-based stress reduction on emotion regulation and test anxiety in female high school students. J Educ Health Promot 2017;6:87 